\title{
Defect formation energetics at the grain boundary in CulnSe 2 using first-principles calculations
}

\author{
Hiroyuki YAMAGUCHI and Teruyasu MIZOGUCHI ${ }^{\dagger}$ \\ Institute of Industrial Science, University of Tokyo, 4-6-1 Komaba, Meguro, Tokyo 153-8505, Japan
}

We investigated defect formation energetics at the grain boundary (GB) in CuInSe $\mathrm{C}_{2}$ (CIS) using first-principles calculations. We focused on the (112)[110] $\sum 3$ twin GB in CIS because this GB is known to be easily formed in CIS. Formation energies and accompanied atomic relaxation of neutral $\mathrm{Cu}$, In, and Se vacancies $\left(\mathrm{V}_{\mathrm{Cu}}{ }^{0}, \mathrm{~V}_{\mathrm{In}}{ }^{0}\right.$, and $\left.\mathrm{V}_{\mathrm{Se}}{ }^{0}\right)$, the $\mathrm{In}$ antisite defect $\left(\operatorname{In}_{\mathrm{Cu}}{ }^{0}\right)$, and the Schottky defect $\left(\mathrm{In}_{\mathrm{Cu}}{ }^{2+}+2 \mathrm{~V}_{\mathrm{Cu}}{ }^{-}\right)$were investigated in the bulk and GB. We found that CIS shows characteristic atomic relaxation after vacancy formation, and $\mathrm{V}_{\mathrm{Cu}}{ }^{0}$ is the most energetically favorable defect in both the bulk and the GB. Furthermore, we found that (112)[110] $\sum 3$ twin GB does not promote the formation of the $\mathrm{Cu}$ vacancy under all conditions, whereas it relatively promotes the formation of the Se vacancy under metal-rich conditions.

(C2014 The Ceramic Society of Japan. All rights reserved.

Key-words : Photovoltaic cell, CulnSe2, First principles calculation

[Received December 15, 2013; Accepted February 26, 2014]

\section{Introduction}

$\mathrm{CuInSe}_{2}$ (CIS) has attracted great interest as a material for the photo-absorption layer in thin-film photovoltaic devices because it has a direct band gap and the band gap is tunable by making a solid solution. ${ }^{1)}$ CIS and its solid solutions have been extensively studied, and the solar ray conversion efficiency recently reached $20 \%$ by making a solid solution with $\mathrm{CuGaSe}_{2}[\mathrm{Cu}(\mathrm{In}, \mathrm{Ga})-$ $\left.\mathrm{Se}_{2}\right]^{2), 3)}$ Through the previous studies, it was revealed that the vacancy formation behavior of these materials is crucial for the photo-absorption property because extra bands are formed in the band gap by the vacancies. Thus, the vacancy formation behavior of CIS-type materials has been studied theoretically and experimentally, ${ }^{4)-8)}$ and it has been reported that neutral $\mathrm{Cu}$ vacancy $\left(\mathrm{V}^{0} \mathrm{Cu}\right)$ and defects pair $\left(\mathrm{In}_{\mathrm{Cu}}{ }^{2+}+2 \mathrm{~V}_{\mathrm{Cu}}{ }^{-}\right)$are preferably formed in CIS. ${ }^{4), 7)}$

However, most of previous studies focused on the vacancy formation inside the CIS bulk, despite the fact that CIS used in the photovoltaic devices is a polycrystalline material. That is, many grain boundaries (GB) are present in the photo-absorption layers. ${ }^{9)}$ Although it is expected that the GB influences the vacancy formation behavior, ${ }^{10)-12)}$ the details of the vacancy formation behavior at the GBs in CIS have not been clarified.

Here, we investigated the defect formation energies of intrinsic defects at the GB of CIS using a first-principles projector augmented wave (PAW) method based on density functional theory (DFT). We focused on a (112) [1 110$] \sum 3$ twin GB of CIS, because this twin GB is known to be easily formed in CIS and related materials. ${ }^{13)}$ In this study, we have calculated the vacancy formation energies of neutral $\mathrm{Cu}$, In, and $\mathrm{Se}$ vacancies $\left(\mathrm{V}^{0} \mathrm{Cu}\right.$, $\left.\mathrm{V}^{0}{ }_{\mathrm{In}}, \mathrm{V}^{0} \mathrm{Se}\right)$, antisite $\mathrm{In}$ on the $\mathrm{Cu}$ site $\left(\operatorname{In}_{\mathrm{Cu}}{ }^{0}\right)$, and a Schottky type defect $\left(\mathrm{In}_{\mathrm{Cu}}{ }^{2+}+2 \mathrm{~V}_{\mathrm{Cu}}{ }^{-}\right)$. In addition, the site dependence of the vacancy formation at the GB is discussed.

\footnotetext{
Corresponding author: T. Mizoguchi; E-mail: teru@iis.u-tokyo. ac.jp

* Preface for this article: Dol http://dx.doi.org/10.2109/jcersj2.122.P6-1
}

\section{Methods}

Figure 1(a) shows the unit cell of the chalcopyrite CIS structure. ${ }^{14)}$ Viewing this from the $[1 \overline{1} 0]$ axis, the dumbbell structure consists of $\mathrm{Cu} / \mathrm{In}$ and Se columns. The stable atomic structure of the (112)[1ㅣㅣ $\sum 3$ twin GB was determined in previous work using high resolution transmission electron microscopy and firstprinciples calculations. ${ }^{15)}$ The lattice vectors of each direction and the dimensions of the supercell were $X=[221]$ (40.82 $\AA$ ), $\mathrm{Y}=[11 \overline{1}] \quad(7.22 \AA)$ and $\mathrm{Z}=[1 \overline{1} 0](8.37 \AA)$. This supercell included 96 atoms. To introduce the vacancy, this supercell was repeated $1 \times 2 \times 2$ in the [221], [11 1 ] and [1 10$]$ directions, and a 384 atom supercell was constructed.

In the calculations, we used the first-principles projector augmented-wave (PAW) method based on density functional (a)
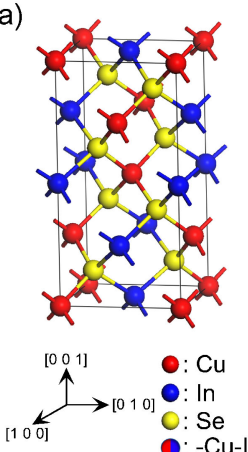

O: - $\mathrm{Cu}-\mathrm{In}-\mathrm{Cu}-$

\begin{tabular}{lrc}
\hline & Cal. & Exp.(Ref.[14]) \\
\hline $\mathrm{a}(\AA)$ & 5.883 & 5.784 \\
$\mathrm{c}(\AA)$ & 11.864 & 11.616 \\
\hline
\end{tabular}

(b)

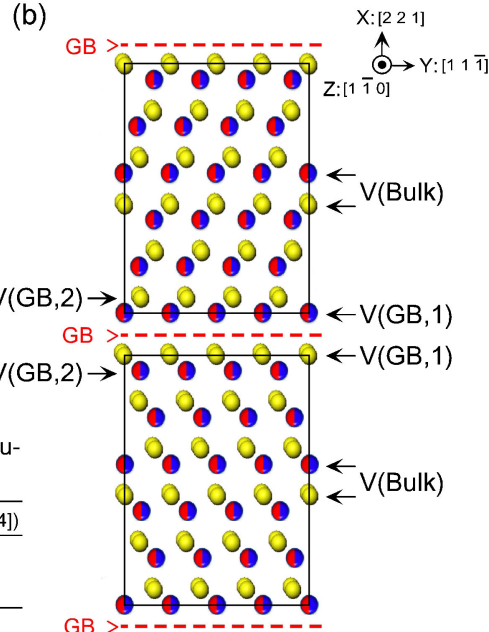

Fig. 1. (a) Atomic structure of the $\mathrm{CuInSe}_{2}$ unit cell and the calculated and experimental lattice constants. (b) Schematic view of the (112)[110] $\sum 3$ twin $\mathrm{GB}$. $\mathrm{V}(\mathrm{GB}, 1)$ and $\mathrm{V}(\mathrm{GB}, 2)$ denote the first and second nearest neighbor sites to GB, and $\mathrm{V}(\mathrm{Bulk})$ denotes the bulk interior site. 
Table 1. Chemical potentials of the three elements at the equilibrium points in Fig. 2

\begin{tabular}{cccc}
\hline & $\mu_{\mathrm{Cu}}$ & $\mu_{\mathrm{In}}$ & $\mu_{\mathrm{Se}}$ \\
\hline A & $\frac{1}{2}\left(\mu_{\mathrm{Cu}_{2} \mathrm{Se}}-\mu_{\mathrm{Se}}\right)$ & $\mu_{\mathrm{CuInSe}_{2}}-\frac{1}{2}\left(\mu_{\mathrm{Cu}_{2} \mathrm{Se}}+3 \mu_{\mathrm{Se}}\right)$ & $\mu_{\mathrm{Se}}$ \\
B & $\mu_{\mathrm{CuInSe}_{2}}-\frac{1}{2}\left(\mu_{\mathrm{In}_{2} \mathrm{Se}_{3}}+\mu_{\mathrm{Se}}\right)$ & $\frac{1}{2}\left(\mu_{\mathrm{In}_{2} \mathrm{Se}_{3}}-3 \mu_{\mathrm{Se}}\right)$ & $\mu_{\mathrm{Se}}$ \\
C & $\mu_{\mathrm{CuInSe}_{2}}-\frac{1}{3}\left(2 \mu_{\mathrm{In}_{2} \mathrm{Se}}-\mu_{\mathrm{In}}\right)$ & $\mu_{\mathrm{In}}$ & $\frac{1}{3}\left(\mu_{\mathrm{In}_{2} \mathrm{Se}_{3}}-2 \mu_{\mathrm{In}}\right)$ \\
D & $\mu_{\mathrm{Cu}}$ & $\mu_{\mathrm{In}}$ & $\frac{1}{2}\left(\mu_{\mathrm{CuInSe}_{2}}-\mu_{\mathrm{Cu}}-\mu_{\mathrm{In}}\right)$ \\
E & $\mu_{\mathrm{Cu}}$ & $\mu_{\mathrm{CuInSe}_{2}}-2 \mu_{\mathrm{Cu}_{2} \mathrm{Se}}+3 \mu_{\mathrm{Cu}}$ & $\mu_{\mathrm{Cu}_{2} \mathrm{Se}}-2 \mu_{\mathrm{Cu}}$ \\
\hline
\end{tabular}

theory (DFT) within the Perdew-Burke-Ernzerhof (PBE) generalized gradient approximation using the Hubbard $U$ correction $($ GGA $+U)$ with the VASP code. ${ }^{16)}$ As the $U$ parameter, we used $U-J=5 \mathrm{eV}$ on the $\mathrm{Cu} d$ orbitals. ${ }^{17)}$ The cutoff energy of the plane wave was set to $400 \mathrm{eV}$, and the calculated numerical integrations over the Brillouin zone were performed at the $\Gamma$ point. The calculated band gap of CIS using these calculation conditions was $0.98 \mathrm{eV}$, which is good agreement the experimental value of $1.04 \mathrm{eV}^{18)}$

To introduce a $\mathrm{Cu}$, In or Se vacancy, an atom was removed from the supercell. It is known that the formation energies depend on the atomic sites at the GBs, so the calculated defect formation energies were a $\mathrm{Cu}$, In, or Se vacancy at the first nearest neighbor site to the GB, at the second nearest neighbor site to the GB, and in the bulk interior site, which are denoted as $\mathrm{V}(\mathrm{GB}, 1), \mathrm{V}(\mathrm{GB}, 2)$, and $\mathrm{V}$ (Bulk), respectively in Fig. 1(b). To take account of atomic relaxation around a vacancy, all the atoms in the supercell were allowed to relax with the volume fixed. The atomic relaxation was performed until the residual forces of the relaxed atoms were less than $0.1 \mathrm{eV} / \AA$.

The defect formation energies were calculated from the total energies of the supercells based on the standard formalism introduced by Zhang and Northrup. ${ }^{19)}$ In this case, the defect formation energies depend on the atomic chemical potentials of $\mathrm{Cu}, \mathrm{In}$, and Se. The formation energy of a defect is given by

$$
\begin{aligned}
E_{f}= & E_{T}(\text { defect }: q) \\
& -\left\{E_{T}(\text { perfect })-n_{\mathrm{Cu}} \mu_{\mathrm{Cu}}-n_{\mathrm{In}} \mu_{\mathrm{In}}-n_{\mathrm{Se}} \mu_{\mathrm{Se}}\right\} \\
& +q\left(\varepsilon_{F}+E_{\mathrm{VBM}}\right) .
\end{aligned}
$$

Here, $E_{T}($ defect: $q)$ and $E_{T}$ (perfect) are the total energies of the supercell containing a defect in a charged state $q$ and the supercell without any defects, respectively. $n_{\mathrm{Cu}}, n_{\mathrm{In}}$, and $n_{\mathrm{Se}}$ are the number of $\mathrm{Cu}, \mathrm{In}$, and $\mathrm{Se}$ atoms removed from the GB supercell to introduce a vacancy. $\mu_{\mathrm{Cu}}, \mu_{\mathrm{In}}$, and $\mu_{\mathrm{Se}}$ are the atomic chemical potentials, and $\varepsilon_{\mathrm{F}}$ is the Fermi energy measured from the valence band maximum (VBM). In previous studies, band gap correction was performed in the neutral anion vacancy because DFT-GGA calculations usually underestimate the band gap. ${ }^{20)-23)}$ In this study, however, we did not perform the band gap correction because the present calculation reproduces the band gap well, as mentioned above. To determine the atomic chemical potentials in the above equilibrium states, the total energies of the bulk systems of $\mathrm{Cu}(f c c)$, In $(F 4 / m m m)$, Se $\left(P 3_{1} 21\right), \mathrm{Cu}_{2} \mathrm{Se}(F m \overline{3} m)$, and $\operatorname{In}_{2} \mathrm{Se}_{3}\left(P 6_{1}\right)$ were calculated.

The chemical potentials were determined from the equilibrium conditions of the related phases. Figure 2 shows a schematic phase diagram of the ternary $\mathrm{Cu}-\mathrm{In}-\mathrm{Se}$ system, and the vertices of the three phase regions are denoted A-E. Under the assumption that CIS is always stable, the chemical potentials of the three elements were obtained from combinations of the chemical

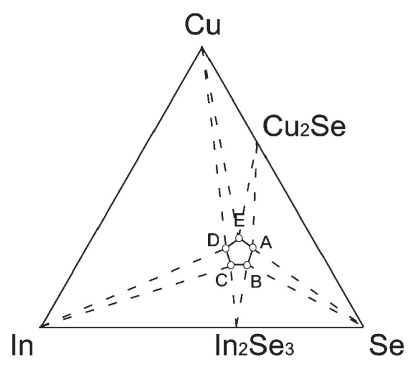

Fig. 2. Schematic phase diagram of the ternary $\mathrm{Cu}-\mathrm{In}-\mathrm{Se}$ system. The vertex at the center corresponds to CIS.

potentials of $\mathrm{Cu}, \mathrm{Cu}_{2} \mathrm{Se}, \mathrm{In}, \mathrm{In}_{2} \mathrm{Se}_{3}$, and $\mathrm{Se}$, and the chemical potentials satisfy the following correlation:

$$
\mu_{\mathrm{Cu}}+\mu_{\mathrm{In}}+2 \mu_{\mathrm{Se}}=\mu_{\mathrm{CIS}(\text { bulk })},
$$

where $\mu_{\mathrm{CIS} \text { (bulk) }}$ is the total energy per formula unit of the perfect CIS crystal. At each point A-E in the phase diagram of Fig. 2, CIS is the equilibrium with the constitute elements, so the chemical potentials are constrained by the equations in Table $\mathbf{1}$. According to the phase diagram in Fig. 2, points A and B correspond to Se-rich conditions because the system is in equilibrium with selenium, while point $\mathrm{D}$ corresponds to metallic conditions because the system is in equilibrium with the $\mathrm{Cu}$ and In metals.

In an actual process of the CIS layer in photovoltaic devices, $\mathrm{Cu}$ and In metals are deposited on a substrate and selenization of the metallic layer is performed. ${ }^{1), 24), 25)}$ That is, the manufacture of CIS is performed under Se-rich conditions. Thus, points A and B correspond to the actual process conditions.

\section{Results and discussion}

First, we investigated the atomic relaxation accompanied with vacancy formation. Similar to the previous study, the magnitude of the atomic relaxation was estimated from the distance between the vacancy site and the first nearest neighbor atoms. ${ }^{10), 21), 22)}$ We averaged the value when there was more than one nearest neighbor bond. The magnitude of the atomic relaxation was calculated by following equation;

$$
\begin{aligned}
& \text { Magnitude of the atomic relaxtaion } \\
& =\left(L_{\text {vacancy }}-L_{\text {perfect }}\right) / L_{\text {perfect }} \text {. }
\end{aligned}
$$

$L_{\text {vacancy }}$ is distance from vacancy site to neighboring atoms and $L_{\text {perfect }}$ is distance between atoms in perfect bulk. The values were represented by percentage. Table 2 lists the magnitude of the atomic relaxation of the vacancies. In addition to CIS, the results in the reference compounds $\mathrm{Si}, \mathrm{GaAs}$, and $\mathrm{BaTiO}_{3}$ are also given for comparison. The negative and positive values indicate atomic relaxation towards and away from the vacancy site, respectively. 
Table 2. Structural relaxations from each vacancy site (Bulk, GB, 1, and $\mathrm{GB}, 2$ ) to the neighboring ions of CIS, $\mathrm{Si}, \mathrm{GaAs}$, and $\mathrm{BaTiO}_{3}$ in $\%$

\begin{tabular}{lcrrr}
\hline & $(\%)$ & Bulk & GB,1 & \multicolumn{1}{c}{ GB,2 } \\
\hline CIS & $\mathrm{V}_{\mathrm{Cu}}^{0}-\mathrm{Se}$ & -4.2 & -4.8 & -4.4 \\
& $\mathrm{~V}_{\mathrm{In}}^{0}-\mathrm{Se}$ & -9.6 & -10.3 & -8.7 \\
& $\mathrm{~V}_{\mathrm{Se}}^{0}-\mathrm{Cu}$ & 21.8 & 26.9 & 21.3 \\
& $\mathrm{~V}_{\mathrm{Se}}^{0}-\mathrm{In}$ & -17.7 & -19.1 & -18.0 \\
\hline $\mathrm{Si}$ & $\mathrm{V}_{\mathrm{Si}}^{0}-\mathrm{Si}$ & -4.3 & & \\
$\mathrm{GaAs}$ & $\mathrm{V}_{\mathrm{Ga}}^{0}-\mathrm{As}$ & -6.6 & & \\
& $\mathrm{~V}_{\mathrm{As}}^{0}-\mathrm{Ga}$ & -7.2 & & \\
$\mathrm{BaTiO}_{3}$ & $\mathrm{~V}_{\mathrm{Ba}}^{0}-\mathrm{O}$ & 1.7 & & \\
$\left(\operatorname{Ref}_{[}[22]\right)$ & $\mathrm{V}_{\mathrm{Ti}}^{0}-\mathrm{O}$ & 8.6 & & \\
& $\mathrm{~V}_{\mathrm{O}}^{0}-\mathrm{Ba}$ & 2.4 & & \\
& $\mathrm{~V}_{\mathrm{O}}^{0}-\mathrm{Ti}$ & 10.4 & & \\
\hline
\end{tabular}

In the bulk interior, the magnitude of the relaxation for $\mathrm{V}_{\mathrm{Cu}}{ }^{0}$ is small $(-4.2 \%)$ and that for $\mathrm{V}_{\mathrm{In}}{ }^{0}$ is approximately twice that of $\mathrm{V}_{\mathrm{Cu}}{ }^{0}(-9.6 \%)$. On the other hand, relatively large distortions are present for $\mathrm{V}_{\mathrm{Se}^{0}}{ }^{0}(21.8 \%$ or $-17.7 \%)$. The differences in the magnitude of the relaxation can be explained by the ionic size of each element, that is, $\mathrm{Cu}$ is smaller than In, and Se is much larger than the other ions. Furthermore, it is notable that the direction of the relaxation is also dependent on the vacancy species. In the cases of $\mathrm{V}_{\mathrm{Cu}}{ }^{0}$ and $\mathrm{V}_{\mathrm{In}}{ }^{0}$, the neighboring Se ions move towards the vacancy, whereas in the case of $\mathrm{V}_{\mathrm{Se}}{ }^{0}$ the neighboring $\mathrm{Cu}$ ions move away from the vacancy and the neighboring In ions move towards the vacancy. We also investigated the atomic relaxation of charged vacancies and confirmed that the trend of relaxation is not dependent on the charge state of the vacancy. Comparing with the reference materials listed in Table 2, the atomic relaxation in CIS resembles that of a covalent materials, such as $\mathrm{Si}$ and $\mathrm{GaAs}$, rather than ionic materials, such as $\mathrm{BaTiO}_{3}$. Actually, a Mulliken population analysis using a first principles plane wave pseudopotential calculation (CASTEP code) indicated that chemical bonding in CIS, especially the $\mathrm{Cu}-\mathrm{Se}$ bonding, has strong covalent character. ${ }^{26), 27)}$

In the vicinity of the $\mathrm{GB}$, the atomic relaxation for $\mathrm{Cu}$ and $\mathrm{In}$ vacancies are basically the same as that in the bulk interior. That is, the relaxation for $\mathrm{V}_{\mathrm{Cu}}{ }^{0}$ and $\mathrm{V}_{\mathrm{In}}{ }^{0}$ are approximately -4 to $-5 \%$ and -8 to $-10 \%$, respectively. However, we found that the $\mathrm{V}_{\mathrm{Se}}{ }^{0}$ at the GB shows larger relaxation than that in the bulk $(21.8 \%$ in the bulk and $26.9 \%$ in the GB). This difference can be attributed to the electronic structure of CIS. Because the valence band of CIS, which is responsible for chemical bonding, is mainly composed of Se components, the electronic structure of Se can be more sensitive to the local atomic coordination than the electronic structures of $\mathrm{Cu}$ and $\mathrm{In}$.

Figure 3 shows the formation energies of $\mathrm{Cu}$, In, and $\mathrm{Se}$ vacancies, antisite $\mathrm{In}$ on the $\mathrm{Cu}$ site, and a Schottky defect $\left(\mathrm{In}_{\mathrm{Cu}}{ }^{2+}+2 \mathrm{~V}_{\mathrm{Cu}}{ }^{-}\right)$in bulk CIS at each point in the phase diagram shown in Fig. 2. In the Schottky-type defect, charged defects were calculated and the formation energy per defect was calculated for comparison. From Fig. 3, the formation energies of $\mathrm{V}_{\mathrm{Cu}}{ }^{0}$ and $\mathrm{V}_{\mathrm{In}}{ }^{0}$ decrease under Se-rich conditions (points $\mathrm{A}$ and $\mathrm{B}$ ), whereas they increase under metal-rich conditions (point D). On the other hand, the vacancy formation energy of Se is high under Se-rich conditions (points A and B), and it decreases under metalrich conditions (point $\mathrm{D}$ ). At point $\mathrm{D}$, the formation energy of $\mathrm{V}_{\mathrm{Se}}{ }^{0}$ is comparable to that of $\mathrm{V}_{\mathrm{Cu}}{ }^{0}$. The antisite $\operatorname{In}_{\mathrm{Cu}}{ }^{0}$ defect shows a similar tendency to the $\mathrm{V}_{\mathrm{Se}}{ }^{0}$ : it is more preferable under metal-rich than Se-rich conditions. Furthermore, it was found that a defect pair $\left(\mathrm{In}_{\mathrm{Cu}}{ }^{2+}+2 \mathrm{~V}_{\mathrm{Cu}}{ }^{-}\right)$shows relatively low formation

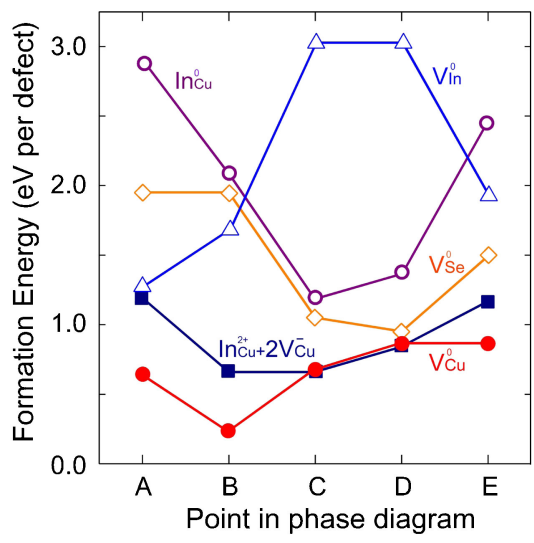

Fig. 3. Calculated formation energies of $\mathrm{V}_{\mathrm{Cu}}{ }^{0}, \mathrm{~V}_{\mathrm{In}}{ }^{0}, \mathrm{~V}_{\mathrm{Se}}{ }^{0}, \mathrm{In}_{\mathrm{Cu}}{ }^{0}$, and $\mathrm{In}_{\mathrm{Cu}}{ }^{2+}+2 \mathrm{~V}_{\mathrm{Cu}}{ }^{-}$at each equilibrium point indicated in Fig. 2.

Table 3. Differences of formation energy $\left(\Delta E_{\mathrm{f}}\right)$ between the bulk interior and the GB

\begin{tabular}{ccc}
\hline$(\mathrm{eV})$ & $\Delta E_{f}(\mathrm{~GB}, 1-\mathrm{Bulk})$ & $\Delta E_{f}(\mathrm{~GB}, 2-\mathrm{Bulk})$ \\
\hline $\mathrm{V}_{\mathrm{Cu}}^{0}$ & 0.00 & -0.08 \\
$\mathrm{~V}_{\mathrm{In}}^{0}$ & -0.02 & -0.09 \\
$\mathrm{~V}_{\mathrm{Se}}^{0}$ & -0.21 & 0.00 \\
$\mathrm{In}_{\mathrm{Cu}}^{0}$ & -0.15 & -0.17 \\
$\mathrm{In}_{\mathrm{Cu}}^{2+}+2 \mathrm{~V}_{\mathrm{Cu}}^{-}$ & -0.06 & 0.08 \\
\hline
\end{tabular}

energy under both Se-rich and metal-rich conditions, and it is preferable under In-rich conditions (points $\mathrm{C}$ and D). From Fig. 3, we concluded that $\mathrm{V}_{\mathrm{Cu}}{ }^{0}$ is the preferable vacancy under all conditions, and $\mathrm{V}_{\mathrm{Se}}{ }^{0}$ and the $\mathrm{In}_{\mathrm{Cu}}{ }^{2+}+2 \mathrm{~V}_{\mathrm{Cu}}{ }^{-}$Schottky defect can be present under metal-rich conditions. The tendency that the formation of $\mathrm{V}_{\mathrm{Cu}}{ }^{0}$ is lower than other vacancies in our calculations, especially under Se-rich conditions, is identical to the conclusions of previous reports. ${ }^{4), 27), 28)}$

Next, the defect formation energies in the vicinity of the GB and in the bulk were compared. To confirm the site dependence of vacancy formation at the GB, the difference in the vacancy formation energy between the bulk and the GB were calculated. ${ }^{10}$ ) Hereafter, this value is denoted $\Delta E_{\mathrm{f}}$. Since $\Delta E_{\mathrm{f}}$ represents a relative value, it does not depend on the atmospheres. Table 3 lists $\Delta E_{\mathrm{f}}$ for $\mathrm{V}_{\mathrm{Cu}}{ }^{0}, \mathrm{~V}_{\mathrm{In}}{ }^{0}, \mathrm{~V}_{\mathrm{Se}}{ }^{0}, \mathrm{In}_{\mathrm{Cu}}{ }^{0}$, and $\mathrm{In}_{\mathrm{Cu}}{ }^{2+}+2 \mathrm{~V}_{\mathrm{Cu}}{ }^{-}$Schottky defects. We found that the $\Delta E_{\mathrm{f}}$ values were very small in most cases, but that for $\mathrm{V}_{\mathrm{Se}}{ }^{0}$ and $\operatorname{In}_{\mathrm{Cu}}{ }^{0}$ were -0.21 and $-0.15 \mathrm{eV}$, respectively. Those $\Delta E_{\mathrm{f}}$ are comparable to that in high angle GB in oxides materials, ${ }^{10)}$ indicating that the formation of $\mathrm{V}_{\mathrm{Se}}{ }^{0}$ and $\operatorname{In}_{\mathrm{Cu}}{ }^{0}$ would be promoted at the GB. However, the concentration of $\operatorname{In}_{\mathrm{Cu}}{ }^{0}$ should be small both at GB and bulk because the absolute formation energy of $\operatorname{In}_{\mathrm{Cu}}{ }^{0}$ is relatively high (Fig. 3).

As mentioned above, the $\mathrm{V}_{\mathrm{Cu}}{ }^{0}$ is preferably formed over the other vacancies under all conditions, and $\mathrm{V}_{\mathrm{Se}}{ }^{0}$ and the $\operatorname{In}_{\mathrm{Cu}}{ }^{2+}+$ $2 \mathrm{~V}_{\mathrm{Cu}}{ }^{-}$Schottky defect can be formed under metal-rich conditions (Fig. 3). Based on those results, we can conclude that the (112)[110] $\sum 3$ twin GB does not promote the formation of the $\mathrm{Cu}$ vacancy irrespective of the atmospheres, whereas it promotes the formation of the Se vacancy in metal-rich conditions.

As mentioned above, the CIS films are fabricated under Serich condition. We revealed that $\mathrm{V}_{\mathrm{Cu}}{ }^{0}$ is energetically favorable under the Se-rich condition and this $\mathrm{V}_{\mathrm{Cu}}{ }^{0}$ does not segregate to the (112)[1 10] $\sum 3$ twin GB. Our conclusion is consistent to an experimental study that significant $\mathrm{V}_{\mathrm{Cu}}$ segregation was not observed in (112)[1 10$] \sum 3$ twin GB of CIS. ${ }^{8)}$ 


\section{Conclusions}

We performed first-principles calculations to understand the defect formation behavior at the (112)[1ํㅣ $\sum 3$ twin GB in $\mathrm{CuInSe}_{2}$ (CIS). We found that atomic relaxation around the vacancy in CIS resembles covalent materials rather than ionic materials. Furthermore, we revealed that the trend of the vacancy formation at the GB is similar to that in the bulk, that is, $\mathrm{V}_{\mathrm{Cu}}{ }^{0}$ is the most preferable defect in all conditions. Through this study, we concluded that the (112)[1 10$] \sum 3$ twin GB does not promote the formation of $\mathrm{Cu}$ vacancies, whereas it promotes the formation of Se vacancies.

Acknowledgements This work was partially supported by the Grant-in-Aid (Nos. 22686059, 23656395, and 25106003) from the MEXT and JSPS, JAPAN, and the special fund of IIS, The University of Tokyo (No. 5504850103). Some calculations were performed using supercomputing system in ISSP, The University of Tokyo. We gratefully acknowledge Professor H. Hiramatsu and Professor H. Hosono for helpful support on CIS fabrication.

\section{References}

1) S. Niki, M. Contreras, I. Repins, M. Powalla, K. Kushiya, S. Ishizuka and K. Matsubara, Prog. Photovolt. Res. Appl., 18, 453-466 (2010).

2) P. Jackson, D. Hariskos, E. Lotter, S. Paetel, R. Wuerz, R. Menner, W. Wischmann and M. Powalla, Prog. Photovolt. Res. Appl., 19, 894-897 (2011).

3) M. A. Green, K. Emery, Y. Hishikawa, W. Warta and E. D. Dunlop, Prog. Photovolt. Res. Appl., 21, 827-837 (2013).

4) S. B. Zhang, S.-H. Wei and A. Zunger, Phys. Rev. Lett., 78, 4059-4062 (1997).

5) S.-H. Wei, S. B. Zhang and A. Zunger, Appl. Phys. Lett., 72, 3199-3201 (1998).

6) S. B. Zhang, S.-H. Wei, A. Zunger and H. Katayama-Yoshida, Phys. Rev. B, 57, 9642-9656 (1998).

7) J. F. Guillemoles, Thin Solid Films, 361/362, 338-345 (2000).

8) Y. Yan, R. Noufi and M. M. Al-Jassim, Phys. Rev. Lett., 96, 205501 (2006).

9) S. Sadewasser, D. Abou-Ras, D. Azulay, R. Baier, I. Balberg, D. Cahen, S. Cohen, K. Gartsman, K. Ganesan, J. Kavalakkatt,
W. Li, O. Millo, Th. Rissom, Y. Rosenwaks, H.-W. Schock, A. Schwarzman and T. Unold, Thin Solid Films, 519, 73417346 (2011).

10) M. Imaeda, T. Mizoguchi, Y. Sato, H.-S. Lee, S. D. Findlay, N. Shibata, T. Yamamoto and Y. Ikuhara, Phys. Rev. B, 78, 245320 (2008).

11) T. Mizoguchi, J. Ceram. Soc. Japan, 119, 325-333 (2011).

12) J. An, J. S. Park, A. L. Koh, H. B. Lee, H. J. Jung, J. Schoonman, R. Sinclair, T. M. Gur and F. B. Prinz, Sci. Rep., 3, 2680 (2013).

13) D. Abou-Ras, B. Schaffer, M. Schaffer, S. S. Schmidt, R. Caballero and T. Unold, Phys. Rev. Lett., 108, 075502 (2012).

14) H. W. Spiess, U. Haeberlen, G. Brandt, A. Rauber and J. Schneider, Phys. Status Solidi, 62, 183-192 (1974).

15) H. Yamaguchi, H. Hiramatsu, H. Hosono and T. Mizoguchi, (submitted).

16) J. P. Perdew, K. Burke and M. Ernzerhof, Phys. Rev. Lett., 78, 3865-3868 (1996).

17) Y. Hinuma, F. Oba, Y. Kumagai and I. Tanaka, Phys. Rev. B, 86, 245433 (2012).

18) J. L. Shay, B. Tell, H. M. Kasper and L. M. Schiavone, Phys. Rev. B, 7, 4485-4490 (1973).

19) S. B. Zhang and J. E. Northup, Phys. Rev. Lett., 67, 2339-2342 (1991).

20) T. Yamamoto and T. Mizoguchi, Phys. Rev. B, 86, 094117 (2012).

21) T. Tanaka, K. Matsunaga, Y. Ikuhara and T. Yamamoto, Phys. Rev. B, 68, 205213 (2003).

22) H.-S. Lee, T. Mizoguchi, T. Yamamoto, S.-J. L. Kang and Y. Ikuhara, Acta Mater., 55, 6535-6540 (2007).

23) K. Matsunaga, T. Tanaka, T. Yamamoto and Y. Ikuhara, Phys. Rev. B, 68, 085110 (2003).

24) A. Rockett and R. W. Birkmire, J. Appl. Phys., 70, R81-R97 (1991).

25) M. Kaelin, D. Rudmann, F. Kurdesau, H. Zogg, T. Meyer and A. N. Tiwari, Thin Solid Films, 480-481, 486-490 (2005).

26) S. J. Clark, M. D. Segall, C. J. Pickard, P. J. Hasnip, M. J. Probert, K. Refson and M. C. Payne, Z. Kristallogr., 220, 567570 (2005).

27) C. Domain, S. Laribi, S. Taunier and J. F. Guillemoles, J. Phys. Chem. Solids, 64, 1657-1663 (2003).

28) T. Maeda and T. Wada, J. Phys. Chem. Solids, 66, 1924-1927 (2005). 